\title{
COVID-19 and thrombosis: Clinical features, mechanism of disease, and therapeutic implications
}

\author{
Francesco Violi ${ }^{1,2}$, Pasquale Pignatelli ${ }^{1,2}$, Vittoria Cammisotto ${ }^{3}$, Simona Bartimoccia ${ }^{4}$, Roberto Carnevale ${ }^{1,4}$, \\ Cristina Nocella ${ }^{2}$
}

${ }^{1}$ Mediterranea Cardiocentro-Napoli, Naples, Italy

2Department of Clinical Internal, Anesthesiological and Cardiovascular Sciences, Sapienza University of Rome, Rome, Italy

${ }^{3}$ Department of General Surgery and Surgical Speciality Paride Stefanini, Sapienza University of Rome, Rome, Italy

${ }^{4}$ Department of Medical-Surgical Sciences and Biotechnologies, Sapienza University of Rome, Latina, Italy

\author{
Correspondence to: \\ Francesco Violi, MD, PhD, \\ Mediterranea Cardiocentro- \\ Napoli, \\ Via Orazio, 2, 80122 Naples, Italy, \\ phone: +3906 49970102 , \\ e-mail: \\ francesco.violi@uniroma1.it \\ Copyright by the Author(s), 2021 \\ Kardiol Pol. 2021; \\ 79 (11): 1197-1205. \\ DOI: 10.33963/KP.a2021.0154 \\ Received: \\ November 8, 2021 \\ Revision accepted: \\ November 11, 2021 \\ Published online: \\ November 25, 2021
}

\begin{abstract}
A B S TR A C T
COVID-19 is a viral respiratory illness caused by the SARS-CoV- 2 infection. In addition to lung disease, clinical complications of COVID-19 include myocardial damage and ischemia-related vascular disease. Severe manifestations and poor prognosis in these patients are associated with a hypercoagulable state predisposing to thrombotic-related complications and eventually death. However, these clinical features can also occur in other forms of pneumonia, such as community-acquired pneumonia (CAP), which, is also complicated by vascular diseases and characterized by platelet activation. Platelets play a pivotal role in these settings as bacteria and viruses may induce activation via Toll-like receptors (TLRs) in CAP patients and different and multiple pathways, including ACE2-Angll axis and/or TLRs, in COVID-19 patients. Despite evidence confirming the implication of platelet activation in both settings, their contribution to the thrombotic process is still under investigation. Thus, in this review, we (1) compare the thrombotic features of SARS-CoV-2 infection and CAP, (2) analyze the putative mechanisms accounting for venous and arterial thrombosis in SARS-CoV-2 infection, and (3) discuss the potential anticoagulant armamentarium to counteract thrombosis.
\end{abstract}

Key words: anticoagulation, COVID-19, platelets, SARS-CoV-2 infection, thrombosis

Kardiol Pol 2021; 79, 11: 1197-1205

\section{INTRODUCTION}

COVID-19 is a pandemic that so far has affected millions of individuals worldwide and greatly increased the risk of morbidity and mortality. Classical clinical features of COVID-19 are represented by the SARS-CoV-2 infection, which is characterized by bilateral ground-glass pneumonia. Pneumonia by COVID-19 may be a serious disease needing mechanical ventilation and intensive care unit (ICU) treatment in old patients or patients with comorbidities, such as coronary heart disease, cardiac failure and arrhythmia, risk factors for atherosclerosis, and chronic obstructive pulmonary disease (COPD) [1]. Even if lung disease with its sequelae greatly con- tributes to the enhanced risk of morbidity and mortality, other clinical features may also contribute to worsening clinical outcomes. Thus, patients with the SARS-CoV-2 infection may experience thrombosis in the venous and arterial circulation, which can aggravate the disease and eventually increase the mortality risk [2]. In accordance with this, analysis of global clotting laboratory tests consistently showed an enhanced circulating level of D-dimer, which results from fibrin degradation by plasmin and, thereby, is considered a marker of hypercoagulation state in patients with the SARS-CoV-2 infection [3]. Changes in other global clotting tests have been also reported, such as prolonged/shortened prothrombin 
time (PT), activated partial thromboplastin time (aPTT), or thrombocytopenia, which suggest that the SARS-CoV-2 infection could be complicated by disseminated intravascular coagulation (DIC). However, this complication has been far demonstrated also because its prevalent clinical feature, i.e, bleeding complications, is rare in the SARS-CoV-2 infection. Therefore, there is consensus that the SARS-CoV-2 infection is essentially complicated by a hypercoagulation state, which is responsible for thrombosis in both venous and arterial circulation [4]. This is of scientific interest as other forms of pneumonia such as, for instance, community-acquired pneumonia (CAP), is complicated by thrombosis essentially in the arterial circulation. Thus, this review aims to compare the thrombotic features of the SARS-CoV-2 infection and CAP, to analyze the putative mechanisms accounting for venous and arterial thrombosis in the SARS-CoV-2 infection, and discuss the potential anticoagulant armamentarium to counteract thrombosis.

\section{THROMBOTIC FEATURES IN SARS-COV-2 AND CAP}

There is a growing body of evidence that clotting, platelet activation, and inhibition of anticoagulant factors may occur in infectious diseases caused by bacteria or viruses [5]. Clinical evidence has been documented in patients with CAP, which may be caused by viruses as well as bacteria [6]. During the hospital stay, patients with CAP may experience myocardial infarction (MI) and stroke, which occur prevalently in old patients or those with serious disease severity [7]. In a large, prospective, multicenter study conducted on more than 1000 patients, $\mathrm{Ml}$ and stroke were detected in $11 \%$ of CAP patients [8]; notably, such complications were a warning sign of poor outcome in short- and long-term follow-up, suggesting the need for appropriate prevention of these vascular diseases $[9,10]$. Conversely, there is no consensus as to whether CAP is complicated by venous thrombosis. In the prospective observational study, we did not observe symptomatic venous thrombosis (VT) in CAP, but we could not exclude a coexistence of asymptomatic VT [11].

At variance with CAP, early data on COVID-19 demonstrated that venous thrombosis is the principal thrombotic feature of SARS-CoV-2; clinical presentations of VT are essentially deep venous thrombosis (DVT) and pulmonary embolism (PE). Mackman et. al analyzed 15 studies from different countries and showed that venous thrombo-embolism was the most frequently reported vascular complication with a very large rate from $0.9 \%$ to $69 \%$. On the other hand, the rate of arterial thrombosis was scarcely represented with an incidence of $2.8 \%-3.8 \%$ [12]. This apparent discrepancy between venous and arterial thrombosis was disproved by a study in a small group of 73 patients, of whom 17 (23\%) experienced an almost similar distribution of venous and arterial thrombosis [13]. Furthermore, a large prospective study conducted in 3334 COVID-19 patients showed an occurrence of thrombotic events in 533 (16\%) during hospitalization - 207 events were in the venous tree $(6.2 \%$ were venous; $3.2 \% \mathrm{PE}$ and $3.9 \% \mathrm{DVT})$ and $365(11 \%)$ in the arterial one $(8.9 \% \mathrm{Ml}, 1.6 \%$ stroke and $1 \%$ thromboembolism) [14]. A similar rate of thrombosis was reported in a smaller group of COVID-19 patients, where the incidence rate during hospitalization was roughly $20 \%$ with an equal distribution between venous and arterial thrombosis [15-17]. Regarding the clinical features of arterial thrombosis, $\mathrm{Ml}$ is the most frequent complication while stroke and arterial thromboembolism are less frequent [18].

Identification of patients at higher risk of thrombosis is an important challenge in the management of COVID-19 patients as it implies their treatment with or without an anticoagulant to prevent the thrombotic risk and eventually lower the mortality rate [19]. There is some evidence that age, sex, and comorbidities, including coronary heart disease, COPD, diabetes, and obesity predispose to thrombosis [20]. Scores, such as pneumonia severity index (PSI) or CURB65, applied to measure disease severity, are also good indicators of poor outcomes, but their relatively low sensitivity precludes their use as thrombosis predictors [21]. There is consistent evidence that patients needing mechanical ventilation or ICU are at higher risk of thrombosis and prescription of anticoagulant at this stage of the disease is mandatory [22]. However, it would be more clinically relevant to identify patients at risk of thrombosis in the early phase of the disease, where therapeutic prophylaxis could prevent thrombosis and its sequelae. So far we have limited information to implement laboratory and/or clinical scores. Some scores such as the PADUA or IMPROVE have been tested in the COVID-19 population to predict thrombosis but, due to the lack of a validation cohort or the analysis of variables, these scores do not fully reflect the clinical picture of the COVID-19 population, and their implementation into clinical practice is difficult $[23,24]$. Among the laboratory variables, D-dimer may represent a useful marker of incipient thrombosis and data are consistent its elevation is closely associated with thrombosis in COVID-19 [14]. Among 2377 patients hospitalized for COVID-19, Berger et al. reported D-dimer elevation in 1823 patients (76\%). The patients with elevated levels of D-dimer were at higher risk to experience a critical illness, thrombosis, and death and, interestingly, the magnitude of D-dimer progressively increased the thrombotic risk with values $>2000 \mathrm{ng} / \mathrm{ml}$ and was significantly associated with thrombosis [25]. The relevance of this interesting finding was undermined by the fact that $10 \%$ of patients with negative D-dimer were also at risk of thrombosis suggesting that $\mathrm{D}$-dimer alone is not useful for thrombotic prediction. Serum albumin is another biomarker potentially useful for thrombosis prediction. Albumin is an acute reactant protein with powerful antioxidant properties related to its richness in thiol groups and with anticoagulant and antiplatelet activity likely related to its antioxidant property; thus, its administration to patients with low serum albumin resulted in platelet aggregation inhibition [26]. Albumin is usually reduced in acute infections because of its involvement as an 
anti-inflammatory molecule [27]. Consequently, albumin is severely lowered in COVID-19 patients with values $<35 \mathrm{~g} / \mathrm{I}$ in most patients with critical illness or needing ICU [28]. This finding may be of interest in exploring the thrombotic risk of COVID-19 as previous studies in the general population on patients at risk of cardiovascular disease reported a close association between serum levels $<35 \mathrm{~g} / \mathrm{l}$ and thrombosis [29]. In line with this, we found that serum levels $<35 \mathrm{~g} / \mathrm{l}$ were significantly associated with $\mathrm{D}$-dimer elevation and an increased risk of thrombosis and death $[13,28]$. In a preliminary study including a small group of COVID-19 patients, we found that albumin infusion at a dosage of $80 \mathrm{~g} /$ day for 3 days followed by $40 \mathrm{~g} /$ day in the following 4 days resulted in a significant reduction of D-dimer [30]. The mechanism accounting for low serum albumin in COVID-19 may be complex including not only its consumption as an anti-inflammatory molecule but also impaired liver synthesis, loss from concomitant renal disease, or impaired nutritional status [31, 32]. Taken together, the data reported here suggest that these two variables, i.e. serum albumin and D-dimer, may be of interest for future stratification of the thrombotic-risk patients not only in COVID-19 but also in other infectious diseases.

\section{THE MECHANISM OF DISEASE}

In addition to macrovascular thrombosis in the venous and arterial circulation, the SARS-CoV-2 infection is characterized by micro-thrombosis occurring in the alveolar-capillary district, where endothelial swelling along with platelet and leucocyte infiltration concur to thrombotic process [33]. Platelet-fibrin thrombi are quite common in autopsy studies performed in lungs taken from SARS-CoV-2 patients; they are detected in $80 \%-100 \%$ of specimen examined [34]. Thus, at least 3 cellular lines, namely platelets, leucocytes, and endothelial cells, are involved in the thrombotic mechanism of thrombosis in COVID-19.

Platelet activation is the key feature of SARS-CoV-2 as documented by early studies reporting the occurrence of thrombocytopenia as a hematological complication in COVID-19 patients [35]. Thrombocytopenia, approximately $100000 / \mu \mathrm{l}$, was detected in $5 \%-18 \%$ of the SARS-CoV-2 population, mostly in patients with severe disease, and was associated with poor survival, which, nonetheless, was not confirmed in following studies [3].

Thrombocytopenia has been interpreted as a consequence of its activation and rapid turnover, and experimental studies consistently showed that platelets are over-activated in SARS-CoV-2 [36-38]. Several markers of ex vivo platelet activation, such as platelet aggregation, platelet biosynthesis of thromboxane B2, or platelet spreading on collagen under flow condition consistently showed that platelets are over-activated. These changes were more frequently observed in patients with severe disease and needing ICU [39].

Previous studies demonstrated that viruses and bacteria may directly or indirectly interact with platelets so eliciting activation [40-42]. Koupenova et al. [43] reported that influenza $A$ virus localizes in platelets and elicits C3 release-dependent neutrophil-DNA release and aggregation via Toll-like receptor 7 (TLR7). Recent studies suggested that this pathway may be implicated in the thrombotic process via Spike protein interaction with TLR4 and eventually activation of cells implicated in the thrombotic process, such as monocytes and leucocytes [44, 45]. Likewise, we found that platelets from SARS-CoV-2 over-express TLR4, which suggests that this may be a potential mechanism accounting for platelet activation [46]. Thus, TLR4 activation yields up-regulation of NOX2, the most important cellular producer of reactive oxidant species (ROS) such as hydrogen peroxide generation $[47,48]$. NOX2 is a key enzyme of the innate immune system, which, intriguingly, is also localized in endothelial cells and platelets $[49,50]$. Human models characterized by the absence of NOX2 (chronic granulomatous disease) demonstrated that NOX2 is a powerful vasoconstrictive molecule (NO) [51] and favors platelet activation via the production of $\mathrm{F} 2$-isoprostanes and NO inactivation [49]. The behavior of NOX2 has been studied in SARS-CoV-2 patients via analysis of its soluble form, which derives essentially from leucocyte and platelet activation, which shows that the enzyme is over-activated with a close relation with thrombotic events occurring during hospitalization [52].

An alternative mechanism of platelet activation may occur via Spike protein binding to angiotensin-converting enzyme 2 (ACE2) upon its cleavage by a serine protease, i.e. TMPRSS2 [36]. COVID-19 RNA has been detected in platelets from patients with severe and non-severe COVID-19, but it is still unclear if this occurs via the Spike protein-ACE2 axis (Figure 1) as there is no agreement that platelets express ACE2 $[36,39]$. Assuming, however, that Spike protein binds to ACE2, which results in expression downregulation and loss of function, this would be associated with human angiotensin II (Ang II) up-regulation as ACE2 degrades Ang II to Ang 1-7 [53]. The ensuing elevated serum levels of Ang II [54,55] could have potentially deleterious effects as Ang II is implicated in artery dysfunction via NOX2-mediated ROS over-production [56] and plays a direct role in platelet activation $[57,58]$. Also, viral particles and RNA viruses could activate platelets via platelet FcyRIIA interaction upon viral particle opsonization by antibodies [43]. However, this would occur at a later stage of the disease with no relation to the early thrombotic events [59].

Finally, overproduction of inflammatory pro-aggregating cytokines such as, for example, tumor necrosis factor a (TNFa) [60], could be another important stimulus for platelet activation as it behaves as a pro-aggregating molecule and is elevated in patients affected by COVID-19 [61]. Further research is necessary to explore this hypothesis.

Despite these experimental data supporting the role of platelets in the thrombogenesis of SARS-CoV-2, few studies found a relationship between platelets and thrombosis in SARS-CoV-2. Barrett et al. reported that soluble CD40L, 


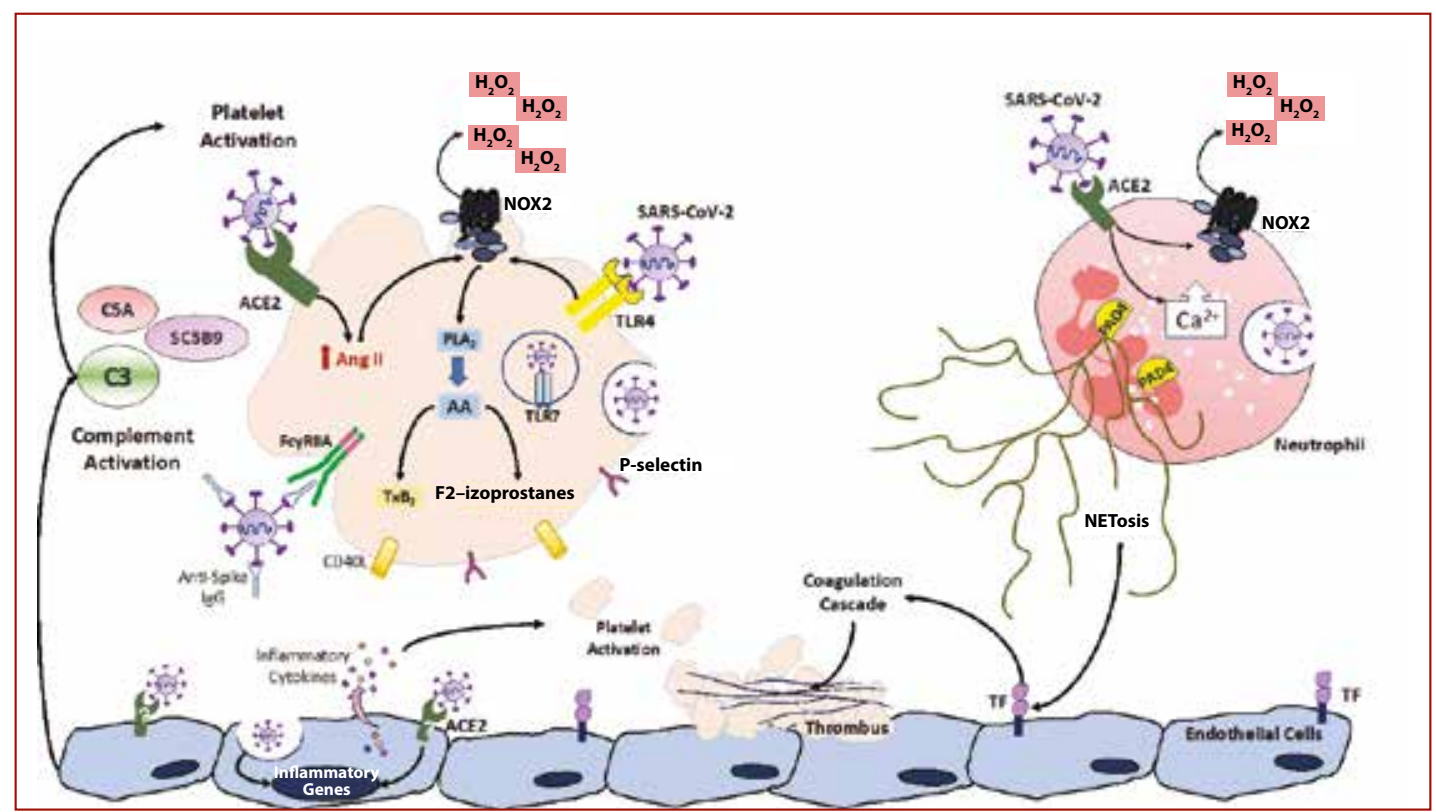

Figure 1. Pathophysiological mechanisms implicated in the thrombotic process mediated by SARS-CoV-2. SARS-CoV-2 produces a series of cellular and molecular events that may be implicated in thrombotic complications. In particular, SARS-CoV- 2 enters platelets, endothelial cells, and leukocytes via binding to ACE2, TLR4, and via endocytosis, causing activation of intra-signaling pathways. SARS-CoV-2 may activate platelets by ACE2 or TLR4, which, in turn, induce NOX2-mediated oxidative stress and increase TXB ${ }_{2}$ P-selectin, and CD40L, further activating platelets, endothelial cells, and leukocytes. In addition, SARS-CoV-2 induces the membrane expression of TF by endothelial cells, thus initiating the coagulation cascade. Moreover, SARS-CoV-2 elicits NETs-derived neutrophils that arrest viruses but also have pro-thrombotic properties. Finally, the complement activation cascade amplifies platelet and leukocytes activation and endothelial dysfunction associated with vascular thrombosis in SARS-CoV-2 infection

Abbreviations: ACE2, angiotensin-converting enzyme 2; Ang II, angiotensin-converting enzyme II; AA, arachidonic acid; CD40L, CD40 ligand; $\mathrm{H}_{2} \mathrm{O}_{2}$, hydrogen peroxide; NETs, neutrophil extracellular traps; PAD4, protein arginine deiminase 4; PLA ${ }_{2}$, phospholipases $\mathrm{A}_{2}$; TLR4, toll-like receptor 4; TF, tissue factor; $\mathrm{TXB}_{2^{\prime}}$ thromboxane $\mathrm{B}_{2}$

P-selectin, and serum $\mathrm{TXB}_{2}$ were independently associated with thrombosis or death. Multiple regression analyses showed, however, that only $\mathrm{TXB}_{2}$ was independently associated with thrombosis [62]. Further data are, therefore, necessary to elucidate the relationship between platelet activation and thrombosis in COVID-19 patients.

Leukocyte activation is another mechanism potentially implicated in the thrombogenesis of SARSCoV-2. A massive presence of leukocytes has been detected in autoptic studies performed in SARS-CoV-2 infected patients $[63,64]$, which may result in thrombus growth as, upon activation, leucocytes may generate NETs, which comprise of DNA and histones and are released upon neutrophil stimulation by patterns recognition receptors or chemokines [65]. Such release requires the formation of ROS and calcium mobilization, which activate protein arginine deaminase 4 (PAD4) to deaminate arginine residues on histones [66]. Autoptic studies in patients with COVID-19 demonstrated the presence of platelets, neutrophils, and NETs in the lung and structures consistent with blood vessels, which suggests that platelet-neutrophil interaction may lead to NETs formation and eventually thrombosis [67-69]. Thus, NETs are powerful prothrombotic molecules via expression of tissue factor (TF), a glycoprotein that converts factor $\mathrm{X}$ to $\mathrm{Xa}[71,71]$. Notably, a significant correlation between circulating NETs and thrombin-antithrombin complexes was detected in the blood of patients with COVID-19 [72]. Also, platelet-rich plasma from SARS-CoV-2 infected subjects co-incubated with normal neutrophils increased the levels of TF mRNA and generated NETs expressing TF [72].

Endothelial dysfunction/damage is another factor contributing to thrombosis in SARS-CoV-2. Electron microscopy of endothelial cells (EC) revealed endothelium congestion with leakage of end-cellular material in the lumen suggesting that SARS-CoV-2 elicits a sort of inflammation-induced endothelitis [73]. Thus, electron microscopy studies showed that the COVID-19 localizes within the endothelial cells, where it can induce cell apoptosis and, eventually, functional changes [74]. It is unclear, however, how COVID-19 gets access to EC as it is uncertain whether ACE2 is expressed by EC [75]. Conversely, pericytes do express ACE2, and studies in alveolar capillaries by SARS-CoV-2-infected lungs showed a marked decrease of these cells, which may also contribute to thrombosis. An important input has been provided by Canzano et al. [76] who showed a marked impaired endothelial biosynthesis of two crucial vasodilator and antiaggregant molecules, such as nitric oxide and prostacyclin (prostaglandin 12, PGI2), which may represent a key factor for platelet activation and thrombus growth. 
Finally, endothelial perturbation and vascular thrombosis can also be promoted by the complement system activation. Regardless of the initial activation step, the cleavage of $\mathrm{C} 3$, subsequent $\mathrm{C} 5$ activation (C5a), and the membrane attack complex formation (MAC/C5b-9) drive neutrophil activation and inflammation that eventually leads to endothelial damage. Several studies analyzed the complement activation in COVID-19 patients, and all three pathways seem to be implicated [77]. Indeed, COVID-19 patients showed higher levels of C4d (classical pathway) [78], C5a and sC5b-9 [78-82] (alternative pathway), and mannose-binding lectin (MBL) pathway [79]. Moreover, enhanced complement activation was more prevalent in patients with severe COVID-19 [80, 82] and associated with biomarkers of endothelial injury [80] and hypercoagulability $[80,83]$.

Besides increased systemic concentrations of complement components, some evidence showed increased local multi-organ complement deposition in the lung and skin [83], kidney, and liver [77, 84] (Figure 1).

\section{THERAPEUTIC IMPLICATIONS}

Based on the clinical presentation of SARS-CoV-2 infected patients, anticoagulants (ACs) have been the first-choice treatment to prevent thrombosis and possibly death. ACs have been given as prophylactic or intermediate-full dosage in COVID-19, and low-molecular-weight heparin (LMWH) was the anticoagulant most extensively used. However, several caveats regarding the usefulness of the therapeutic approach remain, especially considering their use in the cases of severe or non-severe disease such as, for instance, in the ICU vs. non-ICU patients with COVID-19. A recent consensus from the American Society of Hematology recommends the use of a prophylactic dose of LMWH whatever the clinical presentation is while the International Society on Thrombosis and Haemostasis suggests the use of a higher dosage in case of severe critical illness $[85,86]$. The clinical studies did not show a greater benefit of using a high dosage of $A C$, therefore, until new data are reported, the choice of prophylactic dosage of AC is advisable. This issue has been recently addressed by Spyropoulos et al. [87] who randomized 557 COVID-19 patients into a group with a prophylactic/intermediate dosage of LMWH and a group with therapeutic doses of heparin. The patients suffered from severe disease as depicted by $D$-dimer $>4$ times higher the upper limits of normal or sepsis-induced coagulopathy score $>4$ or greater [87]. Spyropoulos et al. found that therapeutic dosage lowered the risk of major thromboembolism and death but was not superior to the other two dosages in ICU patients.

Despite the beneficial effect of $\mathrm{LMWH}$, the thrombotic risk remains elevated, which suggests the need for implementing suppletive therapeutic approaches. It could be argued, for instance, that the robust evidence in favor of coincident platelet activation might suggest combining AC with an antiplatelet drug such as aspirin. We have very little data regarding the effectiveness of aspirin in COVID-19. Chow et al. [88] studied 420 COVID-19 patients, 314 (76.3\%) aspirin-free and 98 (23.7\%) on aspirin within 24 hours from admission or 7 days prior to admission and reported that aspirin use was independently associated with decreased risk of mechanical ventilation $(-46 \%)$, ICU admission (-43\%), and in-hospital mortality (-47\%) while no differences in major bleedings or thrombosis were detected between aspirin users and non-users [88]. This finding, however, must be considered with caution and further studies are necessary to assess if aspirin alone or in combination with AC may lower the thrombotic risk in SARS-CoV-2. Considering, however, that the association of $A C$ with aspirin increases the risk of bleeding, an alternative antiplatelet approach could be considered. We have previously reported, for instance, that glucocorticoids exert an antiplatelet activity by lowering the platelet biosynthesis of $\mathrm{TXB}_{2}$, which may provide a plausible interpretation to why glucocorticoids reduce the risk of $\mathrm{MI}$ in CAP patients [89]. It is worth noting that a recent study reported that glucocorticoids improved survival in COVID-19, but it was not investigated if this beneficial effect could be mediated by changes in the thrombotic risk [90].

TLRs may be another target to inhibit platelet function in COVID-19 patients. Thus, platelets from SARS-CoV-2 infected subjects over-express TLR4, which suggests that TLR4 inhibition may be of potential benefit [46]. This hypothesis is supported by the fact that TLR4 has an important role as a thrombosis stimulus as shown by an experimental model of low-grade endotoxemia-induced arterial thrombosis where an inhibitor of TLR4 significantly reduced thrombus growth [91].

Inhibition of NOX2 may be another intriguing therapeutic perspective as NOX2 has a prominent role in platelet ROS formation and platelet activation [92], and the previous study reported a significant association between its activation and thrombosis in SARS-CoV-2 [52].

Albumin may be another option due to its known antioxidant property. A pilot study in patients with cirrhosis and low serum levels of albumin reported a significant reduction of platelet activation as early as after 3 days of albumin supplementation [26], and a pilot study in COVID-19 patients demonstrated that its infusion for 7 days reduced the levels of D-dimer [30]. Moreover, ACE2 administration or inhibition of Spike protein may represent an interesting therapeutic approach as the experimental study demonstrated that both treatments have a negative effect on thrombus growth [36].

Finally, complement activation has been suggested as a novel therapeutic target. The administration of anti-C5 monoclonal antibody eculizumab led to a marked decline in D-dimer levels, alone [93] or in combination with ruxolitinib, a JAK1/2 inhibitor [94]. Moreover, eculizumab reduced neutrophil counts [93] and C-reactive protein levels [95]. Other C5-blocking monoclonal antibodies include tesidolumab (LFG316), which improved oxygenation and 


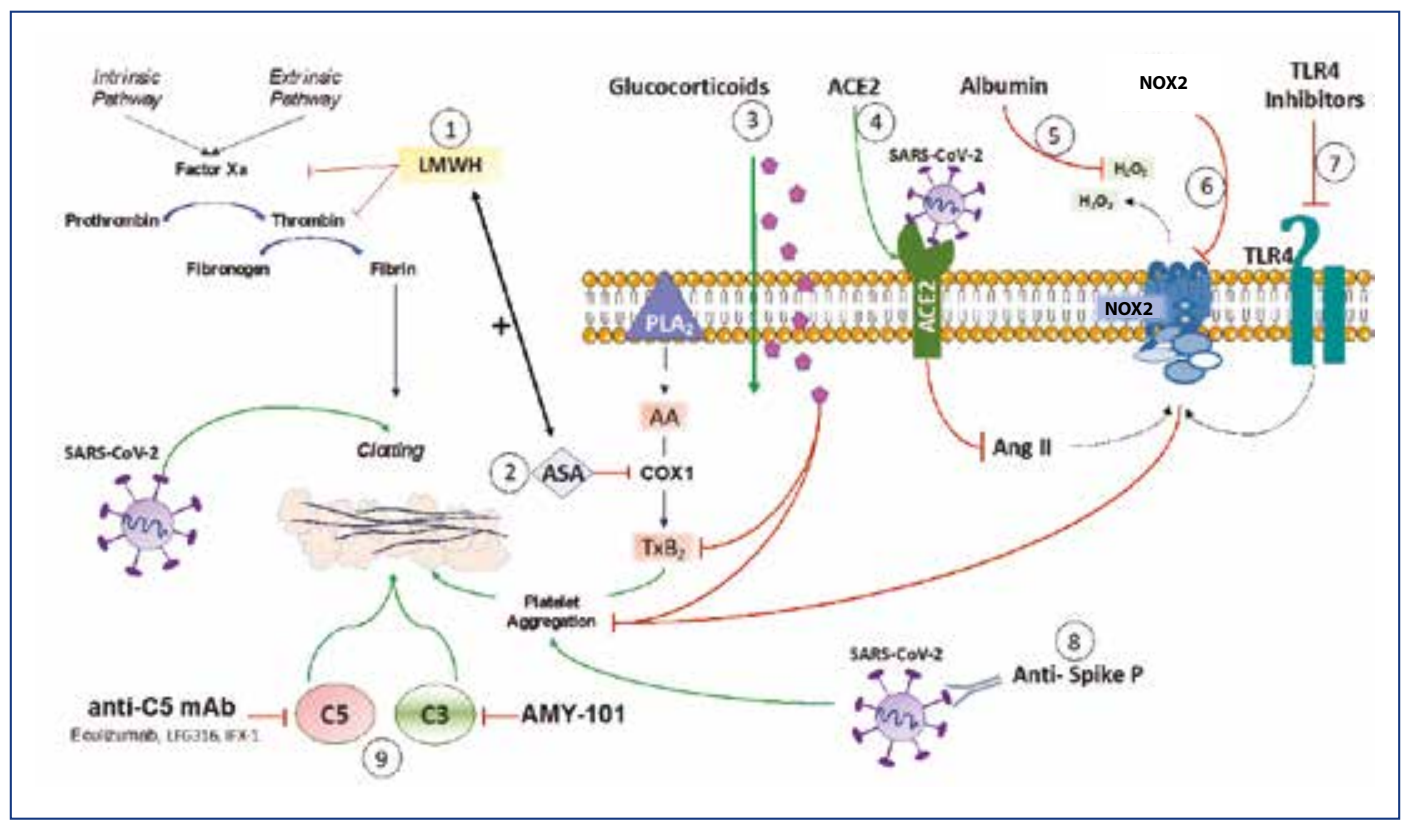

Figure 2. Antithrombotic therapy strategies in COVID-19. Therapeutic approaches to inhibit thrombotic process in COVID-19 patients include (1) anticoagulants (ACs) such as LMWH alone or in association with (2) aspirin, (3) glucocorticoids, (4) ACE2 agonists, (5) Albumin supplementation, inhibitor of (6) NOX2, (7) TLR4, (8) spike protein (P), and (9) complement components. Green arrows: activation pathway. Red arrows: inhibition pathway

Abbreviations: ASA, aspirin; AA, arachidonic acid; Ang II, angiotensin II; ACE2, angiotensin-converting enzyme 2; COX1, cyclooxygenase-1; $\mathrm{H}_{2} \mathrm{O}_{2}$, hydrogen peroxide; LFG316, tesidolumab; LMWH, low-molecular-weight heparin; IFX-1, vilobelimab; PLA2, phospholipases A2; TLR4, toll like receptor 4

reduced the arterial partial pressure of carbon dioxide $\left(\mathrm{PaCO}_{2}\right)$ [96], and vilobelimab (IFX-1), which was tested in phase 2 randomized controlled trial demonstrating its safety and tolerability in patients with severe COVID-19 [97].

Another approach is the use of compstatins (Cp40/AMY-101), highly selective and potent C3 inhibitors. Preliminary clinical results of the administration of AMY-101 indicate a reduction of the systemic hyper-inflammation by reducing C-reactive protein and IL-6 levels and a marked improvement of lung function $[98,99]$.

\section{CONCLUSIONS}

Experimental and clinical studies consistently showed that platelets are activated in CAP and COVID-19 and could play a role in precipitating vascular diseases, which complicates the clinical course of both diseases. The mechanism of platelet and clotting activation may include different and multiple pathways, which appear to be more complex in the case of COVID-19, where the virus might bind to the cells using several entry mechanisms such as the ACE2-Angll axis and/or TLRs (Figure 2). If confirmed, inhibition of these two pathways may be a tool to develop novel antiplatelet strategies. Conversely, it is still unclear if, in the case of CAP, one or more cellular line activation is implicated in the thrombotic process. However, the lower risk of thrombosis, as well as the peculiar thrombosis typical of CAP, suggests that CAP and COVID-19 do not share similar thrombotic mechanisms, with COVID-19 being more frequently complicated by both venous and arterial thromboses while the vascular disease is less frequent in CAP and localized prevalently in the arterial circulation. These findings may have an impact on the antithrombotic strategy as antiplatelet drugs, such as aspirin, could be the first choice for CAP treatment unless the disease severity entails alternative treatment. In the case of COVID-19, the typology of vascular disease indicates AC as the first choice while the contemporary use of antiplatelet drugs is still debated, given the potential bleeding risk. Experimental data, however, support the thesis/assumption that platelets contribute to the thrombotic process and, considering the still elevated residual risk of thrombosis and death, despite AC treatment, a combination of antiplatelet treatment may be an important option to improve clinical outcomes in COVID-19. In this last context, a novel therapeutic combination is needed as the classic combination of AC with antiplatelet drugs, such as aspirin or clopidogrel, is not effective and potentially harmful. Future studies should be launched to develop novel antithrombotic strategies in COVID-19.

\section{Article information}

Conflict of interest: None declared.

Open access: This article is available in open access under Creative Common Attribution-Non-Commercial-No Derivatives 4.0 International (CC BY-NC-ND 4.0) license, allowing to download articles and share them with others as long as they credit the authors and the publisher, but without permission to change them in any way or use them commercially. For commercial use, please contact the journal office at kardiologiapolska@ptkardio.pl. 
How to cite: Violi F, Pignatelli P, Cammisotto V, et al. COVID-19 and thrombosis: Clinical features, mechanism of disease, and therapeutic implications. Kardiol Pol. 2021; 79(11): 1197-1205, doi: 10.33963/KP.a2021.0154.

\section{REFERENCES}

1. Gupta S, Hayek SS, Wang W, et al. Factors associated with death in critically ill patients with coronavirus disease 2019 in the US. JAMA Intern Med. 2020; 180(11):1436-1447, doi: 10.1001/jamainternmed.2020.3596, indexed in Pubmed: 32667668.

2. Violi F, Ceccarelli G, Cangemi R, et al. Thrombosis in COVID-19 and non-COVID-19 pneumonia: role of platelets. Platelets. 2021 [Epub ahead of print]; 16(5): 1-9, doi: 10.1080/09537104.2021.1936478, indexed in Pubmed: 34097572.

3. Violi F, Pastori D, Cangemi R, et al. Hypercoagulation and antithrombotic treatment in coronavirus 2019: a new challenge. Thromb Haemost. 2020; 120(6): 949-956, doi: 10.1055/s-0040-1710317, indexed in Pubmed: 32349133.

4. Warkentin TE, Kaatz S. COVID-19 versus HIT hypercoagulability. Thromb Res. 2020; 196: 38-51, doi: 10.1016/j.thromres.2020.08.017, indexed in Pubmed: 32841919.

5. Violi F, Cangemi R, Calvieri C. Pneumonia, thrombosis and vascular disease. JThromb Haemost. 2014; 12(9): 1391-1400, doi: 10.1111/jth.12646, indexed in Pubmed: 24954194.

6. Wunderink RG, Waterer G, Waterer GW, et al. Management of community-acquired pneumonia in adults. Am J Respir Crit Care Med. 2011; 183(2): 157-164, doi: 10.1164/rccm.201002-0272Cl, indexed in Pubmed: 20693379.

7. Corrales-Medina VF, Musher DM, Wells GA, et al. Cardiac complications in patients with community-acquired pneumonia: incidence, timing, risk factors, and association with short-term mortality. Circulation. 2012 125(6): 773-781, doi: 10.1161/CIRCULATIONAHA.111.040766, indexed in Pubmed: 22219349.

8. Cangemi R, Calvieri C, Taliani G, et al. Relation of cardiac complications in the early phase of community-acquired pneumonia to long-term mortality and cardiovascular events. Am J Cardiol. 2015; 116(4): 647-651, doi: 10.1016/j.amjcard.2015.05.028, indexed in Pubmed: 26089009.

9. Cangemi R, Calvieri C, Falcone $\mathrm{M}$, et al. Relation of cardiac complications in the early phase of community-acquired pneumonia to long-term mortality and cardiovascular events. Am J Cardiol. 2015; 116(4):647-651, doi: 10.1016/j.amjcard.2015.05.028, indexed in Pubmed: 26089009.

10. Corrales-Medina VF, Alvarez KN, Weissfeld LA, et al. Association between hospitalization for pneumonia and subsequent risk of cardiovascular disease. JAMA. 2015; 313(3): 264-274, doi: 10.1001/jama.2014.18229, indexed in Pubmed: 25602997.

11. Loffredo L, Arienti V, Vidili G, et al. Low rate of intrahospital deep venous thrombosis in acutely ill medical patients: results from the AURELIO study. Mayo Clin Proc. 2019; 94(1): 37-43, doi: 10.1016/j.mayocp.2018.07.020, indexed in Pubmed: 30611451.

12. Mackman N, Antoniak S, Wolberg AS, et al. Coagulation abnormalities and thrombosis in patients infected with SARS-CoV-2 and other pandemic viruses. Arterioscler Thromb Vasc Biol. 2020; 40(9): 2033-2044, doi: 10.1161/ATVBAHA.120.314514, indexed in Pubmed: 32657623.

13. Violi F, Ceccarelli $G$, Cangemi R, et al. Hypoalbuminemia, coagulopathy, and vascular disease in COVID-19. Circ Res. 2020; 127(3): 400-401, doi: 10.1161/CIRCRESAHA.120.317173, indexed in Pubmed: 32508261.

14. Bilaloglu S, Aphinyanaphongs $Y$, Jones $S$, et al. Thrombosis in hospitalized patients with COVID-19 in a new york city health system. JAMA. 2020; 324(8): 799-801, doi: 10.1001/jama.2020.13372, indexed in Pubmed: 32702090.

15. Cui S, Chen S, Li X, et al. Prevalence of venous thromboembolism in patients with severe novel coronavirus pneumonia. J Thromb Haemost. 2020; 18(6): 1421-1424, doi: 10.1111/jth.14830, indexed in Pubmed: 32271988.

16. Hippensteel JA, Burnham EL, Jolley SE. Prevalence of venous thromboembolism in critically ill patients with COVID-19. Br J Haematol. 2020; 190(3): e134-e137, doi: 10.1111/bjh.16908, indexed in Pubmed: 32484907.

17. Middeldorp S, Coppens M, van Haaps TF, et al. Incidence of venous thromboembolism in hospitalized patients with COVID-19. J Thromb
Haemost. 2020; 18(8): 1995-2002, doi: 10.1111/jth.14888, indexed in Pubmed: 32369666.

18. Samidurai A, Das A. Cardiovascular complications associated with COVID-19 and potential therapeutic strategies. Int J Mol Sci. 2020; 21(18), doi: 10.3390/ijms21186790, indexed in Pubmed: 32947927.

19. Mehra MR, Desai SS, Kuy S, et al. Cardiovascular disease, drug therapy, and mortality in covid-19. N Engl J Med. 2020; 382(25): e102, doi: 10.1056/NEJMoa2007621, indexed in Pubmed: 32356626; Retraction. N Engl J Med. 2020; 382(26): 2582

20. Lowe GDO. Common risk factors for both arterial and venous thrombosis. Br J Haematol. 2008; 140(5): 488-495, doi: 10.1111/j.13652141.2007.06973.x, indexed in Pubmed: 18275426.

21. $\lg$ A, Moskowitz A, Konanki V, et al. Performance of the CURB-65 score in predicting critical care interventions in patients admitted with community-acquired pneumonia. Ann Emerg Med. 2019; 74(1): 60-68, doi: 10.1016/j.annemergmed.2018.06.017, indexed in Pubmed: 30078659.

22. Minet $C$, Potton $L$, Bonadona $A$, et al. Venous thromboembolism in the ICU: main characteristics, diagnosis and thromboprophylaxis. Crit Care. 2015; 19:287, doi: 10.1186/s13054-015-1003-9, indexed in Pubmed: 26283414.

23. Zeng DX, Xu JL, Mao QX, et al. Association of Padua prediction score with in-hospital prognosis in COVID-19 patients. QJM. 2020; 113(11): 789-793, doi: 10.1093/qjmed/hcaa224, indexed in Pubmed: 32652021.

24. Chen S, Zheng T, Wang S, et al. DVT incidence and risk factors in critically ill patients with COVID-19. JThromb Thrombolysis. 2021;51(1):33-39, doi: 10.1007/s11239-020-02181-w, indexed in Pubmed: 32607652

25. Berger JS, KunichoffD, Adhikari S, et al. Prevalence and outcomes of D-dimer elevation in hospitalized patients with COVID-19. Arterioscler Thromb Vasc Biol. 2020; 40(10): 2539-2547, doi: 10.1161/ATVBAHA.120.314872, indexed in Pubmed: 32840379.

26. Basili $S$, Carnevale $R$, Nocella $C$, et al. Serum albumin is inversely associated with portal vein thrombosis in cirrhosis. Hepatol Commun. 2019; 3(4): 504-512, doi: 10.1002/hep4.1317, indexed in Pubmed: 30976741.

27. Soeters PB, Wolfe RR, Shenkin A. Hypoalbuminemia: pathogenesis and clinical significance. JPEN J Parenter Enteral Nutr. 2019; 43(2): 181-193, doi: 10.1002/jpen.1451, indexed in Pubmed: 30288759.

28. Violi F, Cangemi R, Romiti GF, et al. Is albumin predictor of mortality in COVID-19? Antioxid Redox Signal. 2021; 35(2): 139-142, doi: 10.1089/ars.2020.8142, indexed in Pubmed: 32524832.

29. Chi G, Gibson CM, Liu Y, et al. Inverse relationship of serum albumin to the risk of venous thromboembolism among acutely ill hospitalized patients: Analysis from the APEX trial. Am J Hematol. 2019; 94(1): 21-28, doi: 10.1002/ajh.25296, indexed in Pubmed: 30252149.

30. Violi F, Ceccarelli G, Loffredo L, et al. Albumin supplementation dampens hypercoagulability in COVID-19: a preliminary report. Thromb Haemost. 2021;121(1): 102-105, doi: 10.1055/s-0040-1721486, indexed in Pubmed: 33368057.

31. Johnson AS, Fatemi R, Winlow W. SARS-CoV-2 bound human serum albumin and systemic septic shock. Front Cardiovasc Med. 2020; 7: 153, doi: 10.3389/fcvm.2020.00153, indexed in Pubmed: 33088822.

32. Chen C, Zhang Y, Zhao Xi, et al. Hypoalbuminemia - an indicator of the severity and prognosis of COVID-19 patients: a multicentre retrospective analysis. Infect Drug Resist. 2021; 14: 3699-3710, doi: 10.2147/IDR. S327090, indexed in Pubmed: 34526790.

33. Semeraro $N$, Colucci $M$. The prothrombotic state associated with SARSCoV-2 infection: pathophysiological aspects. Mediterr J Hematol Infect Dis. 2021; 13(1): e2021045, doi: 10.4084/MJHID.2021.045, indexed in Pubmed: 34276914

34. Carsana L, Sonzogni A, Nasr A, et al. Pulmonary post-mortem findings in a series of COVID-19 cases from northern Italy: a two-centre descriptive study. The Lancet Infectious Diseases. 2020; 20(10): 1135-1140, doi: 10.1016/s1473-3099(20)30434-5.

35. Wool GD, Miller JL. The impact of COVID-19 disease on platelets and coagulation. Pathobiology. 2021; 88(1): 15-27, doi: 10.1159/000512007, indexed in Pubmed: 33049751

36. Zhang Si, Liu Y, Wang X, et al. SARS-CoV-2 binds platelet ACE2 to enhance thrombosis in COVID-19. J Hematol Oncol. 2020; 13(1): 120, doi: 10.1186/s13045-020-00954-7, indexed in Pubmed: 32887634.

37. Brambilla $M$, Canzano $P$, Becchetti $A$, et al. Alterations in platelets during SARS-CoV-2 infection. Platelets. 2021 [Epub ahead of print]: 1-9, doi: 10.1080/09537104.2021.1962519, indexed in Pubmed: 34384321. 
38. Koupenova M, Freedman JE. Platelets and COVID-19:Inflammation, Hyperactivation and Additional Questions. Circ Res. 2020; 127(11): 1419-1421, doi: 10.1161/CIRCRESAHA.120.318218, indexed in Pubmed: 33151798.

39. Manne BK, Denorme F, Middleton EA, et al. Platelet gene expression and function in patients with COVID-19. Blood. 2020; 136(11): 1317-1329, doi: 10.1182/blood.2020007214, indexed in Pubmed: 32573711.

40. Violi F, Cammisotto V, Pignatelli P. Thrombosis in COVID-19 and non-COVID-19 pneumonia: role of platelets. Platelets. 2021 [Epub ahead of print]: 1-9, doi: 10.1080/09537104.2021.1936478, indexed in Pubmed:34097572.

41. Assinger A. Platelets and infection - an emerging role of platelets in viral infection. Front Immunol. 2014; 5: 649, doi: 10.3389/fimmu.2014.00649, indexed in Pubmed: 25566260.

42. Yeaman MR. Platelets in defense against bacterial pathogens. Cell Mol Life Sci. 2010; 67(4): 525-544, doi: 10.1007/s00018-009-0210-4, indexed in Pubmed: 20013024.

43. Koupenova $M$, Corkrey HA, Vitseva $\mathrm{O}$, et al. The role of platelets in mediating a response to human influenza infection. Nat Commun. 2019; 10(1): 1780, doi: 10.1038/s41467-019-09607-x, indexed in Pubmed: 30992428

44. Zhao Y, Kuang M, Li J, et al. SARS-CoV-2 spike protein interacts with and activates TLR41. Cell Res. 2021; 31(7): 818-820, doi: 10.1038/s41422-02100495-9, indexed in Pubmed: 33742149.

45. Choudhury A, Mukherjee S. In silico studies on the comparative characterization of the interactions of SARS-CoV-2 spike glycoprotein with ACE-2 receptor homologs and human TLRs. J Med Virol. 2020; 92(10): 2105-2113, doi: 10.1002/jmv.25987, indexed in Pubmed: 32383269.

46. Oliva A, Cammisotto V, Cangemi R, et al. Low-Grade endotoxemia and thrombosis in COVID-19. Clin Transl Gastroenterol. 2021; 12(6): e00348, doi: 10.14309/ctg.0000000000000348, indexed in Pubmed: 34092777.

47. Violi F, Pignatelli P. Platelet NOX, a novel target for anti-thrombotic treatment. Thromb Haemost. 2014; 111(5): 817-823, doi: 10.1160/TH1310-0818, indexed in Pubmed: 24402688.

48. Nocella C, Carnevale R, Bartimoccia S, et al. Lipopolysaccharide as trigger of platelet aggregation via eicosanoid over-production. Thromb Haemost. 2017; 117(8): 1558-1570, doi: 10.1160/TH16-11-0857, indexed in Pubmed: 28492699.

49. Pignatelli $P$, Carnevale $R$, Cangemi $R$, et al. Atorvastatin inhibits gp91 phox circulating levels in patients with hypercholesterolemia. Arterioscler Thromb Vasc Biol. 2010; 30(2):360-367, doi: 10.1161/ATVBAHA.109.198622, indexed in Pubmed: 19965781.

50. Violi F, Carnevale R, Loffredo L, et al. NADPH oxidase-2 and atherothrombosis: insight from chronic granulomatous disease. Arterioscler Thromb Vasc Biol. 2017; 37(2): 218-225, doi: 10.1161/ATVBAHA.116.308351, indexed in Pubmed: 27932349.

51. Violi F, Loffredo L, Carnevale R, et al. Atherothrombosis and oxidative stress: mechanisms and management in elderly. Antioxid Redox Signal. 2017; 27(14): 1083-1124, doi: 10.1089/ars.2016.6963, indexed in Pubmed: 28816059.

52. Violi F, Oliva A, Cangemi R, et al. NOX2 activation in COVID-19. Redox Biol. 2020; 36: 101655, doi: 10.1016/j.redox.2020.101655, indexed in Pubmed: 32738789.

53. Gheblawi M, Wang K, Viveiros A, et al. Angiotensin-Converting enzyme 2: SARS-CoV-2 receptor and regulator of the renin-angiotensin system: celebrating the 20th anniversary of the discovery of ACE2. Circ Res. 2020; 126(10): 1456-1474, doi: 10.1161/CIRCRESAHA.120.317015, indexed in Pubmed: 32264791.

54. Liu Y, Yang Y, Zhang C, et al. Clinical and biochemical indexes from 2019$\mathrm{nCoV}$ infected patients linked to viral loads and lung injury. Sci China Life Sci. 2020; 63(3): 364-374, doi: 10.1007/s11427-020-1643-8, indexed in Pubmed: 32048163.

55. Wang K, Gheblawi M, Oudit GY. Angiotensin converting enzyme 2: a double-edged sword. Circulation. 2020; 142(5):426-428, doi: 10.1161/CIRCULATIONAHA.120.047049, indexed in Pubmed: 32213097.

56. Molitor M, Rudi WS, Garlapati V, et al. Nox2+ myeloid cells drive vascular inflammation and endothelial dysfunction in heart failure after myocardial infarction via angiotensin II receptor type 1. Cardiovasc Res. 2021; 117(1): 162-177, doi: 10.1093/cvr/cvaa042, indexed in Pubmed: 32077922.

57. Petramala $L$, lacobellis $G$, Carnevale $R$, et al. Enhanced soluble serum CD40L and serum p-selectin levels in primary aldosteronism. Horm Metab Res. 2016; 48(7): 440-445, doi: 10.1055/s-0042-103588, indexed in Pubmed: 27101095.
58. Germanò $G$, Sanguigni V, Pignatelli $P$, et al. Enhanced platelet release of superoxide anion in systemic hypertension: role of AT1 receptors. J Hypertens. 2004; 22(6): 1151-1156, doi: 10.1097/00004872-20040600000016, indexed in Pubmed: 15167450.

59. Zaid Y, Puhm F, Allaeys I, et al. Platelets can associate with SARSCoV-2 RNA and are hyperactivated in COVID-19. Circ Res. 2020 [Epub ahead of print], doi: 10.1161/CIRCRESAHA.120.317703, indexed in Pubmed: 32938299.

60. Pignatelli $P$, De Biase $L$, Lenti $L$, et al. Tumor necrosis factor-alpha as trigger of platelet activation in patients with heart failure. Blood. 2005; 106(6): 1992-1994, doi: 10.1182/blood-2005-03-1247, indexed in Pubmed: 15956282.

61. Fara A, Mitrev Z, Rosalia RA, et al. Cytokine storm and COVID-19: a chronicle of pro-inflammatory cytokines. Open Biol. 2020; 10(9): 200160, doi: 10.1098/rsob.200160, indexed in Pubmed: 32961074.

62. Barrett TJ, Lee AH, Xia Y, et al. Platelet and vascular biomarkers associate with thrombosis and death in coronavirus disease. Circ Res. 2020; 127(7): 945-947, doi: 10.1161/CIRCRESAHA.120.317803, indexed in Pubmed: 32757722.

63. Bösmüller $\mathrm{H}$, Traxler $\mathrm{S}$, Bitzer $\mathrm{M}$, et al. The evolution of pulmonary pathology in fatal COVID-19 disease: an autopsy study with clinical correlation. Virchows Arch. 2020; 477(3): 349-357, doi: 10.1007/s00428-020-02881-x, indexed in Pubmed: 32607684.

64. Valdebenito $S$, Bessis $S$, Annane $D$, et al. COVID-19 lung pathogenesis in SARS-CoV-2 autopsy cases. Front Immunol. 2021; 12: 735922, doi: 10.3389/fimmu.2021.735922, indexed in Pubmed: 34671353.

65. Brinkmann V, Reichard U, Goosmann C, et al. Neutrophil extracellular traps kill bacteria. Science. 2004; 303(5663): 1532-1535, doi: 10.1126/science.1092385, indexed in Pubmed: 15001782.

66. Li P, Li M, Lindberg MR, et al. PAD4 is essential for antibacterial innate immunity mediated by neutrophil extracellular traps. J Exp Med. 2010;207(9): 1853-1862, doi: 10.1084/jem.20100239, indexed in Pubmed: 20733033.

67. DolhnikoffM, Duarte-Neto AN, de Almeida Monteiro RA, et al. Pathological evidence of pulmonary thrombotic phenomena in severe COVID-19. J Thromb Haemost. 2020; 18(6): 1517-1519, doi: 10.1111/jth.14844, indexed in Pubmed: 32294295.

68. Ackermann $M$, Verleden SE, Kuehnel $M$, et al. Pulmonary vascular endothelialitis, thrombosis, and angiogenesis in COVID-19. N Engl J Med. 2020; 383(2): 120-128, doi: 10.1056/NEJMoa2015432, indexed in Pubmed: 32437596.

69. Bradley BT, Maioli $\mathrm{H}$, Johnston $\mathrm{R}$, et al. Histopathology and ultrastructural findings of fatal COVID-19 infections in Washington State: a case series. Lancet. 2020; 396(10247): 320-332, doi: 10.1016/S01406736(20)31305-2, indexed in Pubmed: 32682491.

70. Nadir Y, Brenner B, Fux L, et al. Heparanase enhances the generation of activated factor $X$ in the presence of tissue factor and activated factor VII. Haematologica. 2010; 95(11): 1927-1934, doi: 10.3324/haematol.2010.023713, indexed in Pubmed: 20634491.

71. Folco EJ, Mawson TL, Vromman A, et al. Neutrophil extracellular traps induce endothelial cell activation and tissue factor production through interleukin-1 $a$ and cathepsin G. Arterioscler Thromb Vasc Biol. 2018; 38(8): 1901-1912, doi: 10.1161/ATVBAHA.118.311150, indexed in Pubmed: 29976772.

72. Skendros P, Mitsios A, Chrysanthopoulou A, et al. Complement and tissue factor-enriched neutrophil extracellular traps are key drivers in COVID-19 immunothrombosis. J Clin Invest. 2020; 130(11): 6151-6157, doi: 10.1172/JCl141374, indexed in Pubmed: 32759504.

73. Evans PC, Rainger GEd, Mason JC, et al. Endothelial dysfunction in COVID-19: a position paper of the ESC Working Group for Atherosclerosis and Vascular Biology, and the ESC Council of Basic Cardiovascular Science. Cardiovasc Res. 2020; 116(14): 2177-2184, doi: 10.1093/cvr/cvaa230, indexed in Pubmed: 32750108.

74. Varga $Z$, Flammer AJ, Steiger $P$, et al. Endothelial cell infection and endotheliitis in COVID-19. Lancet. 2020; 395(10234): 1417-1418, doi: 10.1016/S0140-6736(20)30937-5, indexed in Pubmed: 32325026.

75. McCracken IR, Saginc $G, H e$, et al. Lack of evidence of angiotensin-converting enzyme 2 expression and replicative infection by SARS-CoV-2 in human endothelial cells. Circulation. 2021; 143(8): 865-868, doi: 10.1161/CIRCULATIONAHA.120.052824, indexed in Pubmed: 33405941. 
76. Canzano P, Brambilla M, Porro B, et al. Platelet and endothelial activation as potential mechanisms behind the thrombotic complications of COVID-19 patients. JACC Basic TransI Sci. 2021; 6(3): 202-218, doi: 10.1016/j. jacbts.2020.12.009, indexed in Pubmed: 33649738.

77. Noris M, Benigni A, Remuzzi G. The case of complement activation in COVID-19 multiorgan impact. Kidney Int. 2020; 98(2): 314-322, doi: 10.1016/j. kint.2020.05.013, indexed in Pubmed: 32461141.

78. Holter JC, Pischke SE, de Boer E, et al. Systemic complement activation is associated with respiratory failure in COVID-19 hospitalized patients. Proc Natl Acad Sci U S A. 2020; 117(40): 25018-25025, doi: 10.1073/pnas.2010540117, indexed in Pubmed: 32943538.

79. Defendi F, Leroy C, Epaulard O, et al. Complement alternative and mannose-binding lectin pathway activation is associated with COVID-19 mortality. Front Immunol. 2021; 12: 742446, doi: 10.3389/fimmu.2021.742446, indexed in Pubmed: 34567008.

80. Ma L, Sahu SK, Cano M, et al. Increased complement activation is a distinctive feature of severe SARS-CoV-2 infection. bioRxiv. 2021; 6(59), doi: 10.1101/2021.02.22.432177, indexed in Pubmed: 33655244.

81. Carvelli J, Demaria O, Vély F, et al. Association of COVID-19 inflammation with activation of the C5a-C5aR1 axis. Nature. 2020; 588(7836): 146-150, doi: 10.1038/s41586-020-2600-6, indexed in Pubmed: 32726800.

82. Cugno $\mathrm{M}$, Meroni PL, Gualtierotti R, et al. Complement activation in patients with COVID-19: A novel therapeutic target. J Allergy Clin Immunol. 2020; 146(1): 215-217, doi: 10.1016/j.jaci.2020.05.006, indexed in Pubmed: 32417135.

83. de Nooijer AH, Grondman I, Janssen NAF, et al. Complement Activation in the Disease Course of Coronavirus Disease 2019 and Its Effects on Clinical Outcomes. J Infect Dis. 2021;223(2):214-224, doi: 10.1093/infdis/jiaa646, indexed in Pubmed: 33038254.

84. Macor $P$, Durigutto $P$, Mangogna A, et al. Multi-organ complement deposition in COVID-19 patients. medRxiv. 2021; 9(8), doi: 10.1101/2021.01.07.21249116, indexed in Pubmed: 33442701.

85. Spyropoulos AC, Levy JH, Ageno W, et al. Scientific and Standardization Committee communication: Clinical guidance on the diagnosis, prevention, and treatment of venous thromboembolism in hospitalized patients with COVID-19. J Thromb Haemost. 2020; 18(8): 1859-1865, doi: 10.1111/jth.14929, indexed in Pubmed: 32459046.

86. Cuker A, Tseng EK, Nieuwlaat R, et al. American Society of Hematology 2021 guidelines on the use of anticoagulation for thromboprophylaxis in patients with COVID-19. Blood Adv. 2021;5(3):872-888, doi: 10.1182/bloodadvances.2020003763, indexed in Pubmed: 33560401.

87. Spyropoulos AC, Goldin M, Giannis D, et al. Efficacy and Safety of Therapeutic-Dose Heparin vs Standard Prophylactic or Intermediate-Dose Heparins for Thromboprophylaxis in High-risk Hospitalized Patients With COVID-19: The HEP-COVID Randomized Clinical Trial. JAMA Intern Med. 2021 [Epub ahead of print], doi: 10.1001/jamainternmed.2021.6203, indexed in Pubmed: 34617959.
88. Chow JH, Khanna AK, Kethireddy S, et al. Aspirin use is associated with decreased mechanical ventilation, intensive care unit admission, and in-hospital mortality in hospitalized patients with coronavirus disease 2019. Anesth Analg. 2021;132(4):930-941, doi: 10.1213/ANE.0000000000005292, indexed in Pubmed: 33093359.

89. Cangemi R, Carnevale R, Nocella C, et al. Glucocorticoids impair platelet thromboxane biosynthesis in community-acquired pneumonia. Pharmacol Res. 2018; 131: 66-74, doi: 10.1016/j.phrs.2018.03.014, indexed in Pubmed: 29577968.

90. Horby P, Lim WS, Emberson JR, et al. Dexamethasone in hospitalized patients with covid-19. N Engl J Med. 2021;384(8):693-704, doi: 10.1056/NEJMoa2021436, indexed in Pubmed: 32678530.

91. Carnevale R, Sciarretta S, Valenti V, et al. Low-grade endotoxaemia enhances artery thrombus growth via Toll-like receptor 4: implication for myocardial infarction. Eur Heart J. 2020; 41(33): 3156-3165, doi: 10.1093/eurheartj/ehz893, indexed in Pubmed: 31898723.

92. Pignatelli $P$, Sanguigni V, Lenti L, et al. gp91 phox-dependent expression of platelet CD40 ligand. Circulation. 2004; 110(10): 1326-1329, doi: 10.1161/01.CIR.0000134963.77201.55, indexed in Pubmed: 15249506.

93. Laurence J, Mulvey JJ, Seshadri M, et al. Anti-complement C5 therapy with eculizumab in three cases of critical COVID-19. Clin Immunol. 2020; 219: 108555, doi: 10.1016/j.clim.2020.108555, indexed in Pubmed: 32771488.

94. Giudice V, Pagliano P, Vatrella A, et al. Combination of ruxolitinib and eculizumab for treatment of severe SARS-CoV-2-related acute respiratory distress syndrome: a controlled study. Front Pharmacol. 2020; 11:857, doi: 10.3389/fphar.2020.00857, indexed in Pubmed: 32581810.

95. Diurno F, Numis FG, Porta G, et al. Eculizumab treatment in patients with COVID-19: preliminary results from real life ASL Napoli 2 Nord experience. Eur Rev Med Pharmacol Sci. 2020; 24(7): 4040-4047, doi: 10.26355/eurrev_202004_20875, indexed in Pubmed: 32329881.

96. Zelek WM, Cole J, Ponsford MJ, et al. Complement inhibition with the C5 blocker LFG316 in severe COVID-19. Am J Respir Crit Care Med. 2020; 202(9): 1304-1308, doi: 10.1164/rccm.202007-2778LE, indexed in Pubmed: 32897730.

97. Vlaar APJ, de Bruin S, Busch M, et al. Anti-C5a antibody IFX-1 (vilobelimab) treatment versus best supportive care for patients with severe COVID-19 (PANAMO): an exploratory, open-label, phase 2 randomised controlled trial. Lancet Rheumatol. 2020; 2(12): e764-e773, doi: 10.1016/S2665-9913(20)30341-6, indexed in Pubmed: 33015643.

98. Mastellos DC, Pires da Silva BGP, Fonseca BAL, et al. Complement C3 vs C5 inhibition in severe COVID-19: Early clinical findings reveal differential biological efficacy. Clin Immunol. 2020; 220: 108598, doi: 10.1016/j. clim.2020.108598, indexed in Pubmed: 32961333.

99. Mastaglio S, Ruggeri A, Risitano AM, et al. The first case of COVID-19 treated with the complement C3 inhibitor AMY-101. Clin Immunol. 2020; 215: 108450, doi: 10.1016/j.clim.2020.108450, indexed in Pubmed: 32360516. 